\title{
Pemanfaatan tanaman kelor (Moringa oleifera) sebagai hormon tumbuh pada pembibitan tanaman Tebu (Saccharum officinarum $L$.)
}

\author{
(Utilization of moringa (Moringa oleifera) as a growth hormone in Sugarcane (Saccharum \\ officinarum L.) nursery)
}

\author{
M. Rahman, Karno, dan B. A. Kristanto. \\ Agroecotechnology, Faculty of Animal and Agricultural Sciences, Diponegoro University \\ Tembalang Campus, Semarang 50275 - Indonesia \\ Corresponding E-mail: miftahur.12.mr@gmail.com
}

\begin{abstract}
The aim of this research was to determine the doses of Moringa leaf extract in increasing the growth of tillers of several varieties of sugarcane and to determine the difference in response of each variety to the given doses. The research used a complete randomized factorial design with 2 factors and 5 replications. The first factor was the doses of moringa leaf extract $(0,10,20$, and $30 \mathrm{ml} / \mathrm{L})$ and $10 \mathrm{ml} / \mathrm{L}$ of synthetic cytokinin as control and the second factor was 3 different sugarcane varieties (Variety $1=$ BM 9514, variety $2=$ BM 9044, and variety $3=$ BM 9065). The observed parameters were germination, plant height, number of tillers, plant fresh and dry weight, crown fresh and dry weight, root fresh and dry weight, and root volume. The data were analyzed by analysis of variance then tested by Duncan Multiple-Ranged Test (DMRT). The result showed that the highest germination rate at 97,4\% was BM 9605 variety. The application of moringa leaf extract influenced on root volume and there were interaction between dose and variety treatments. Variety treatment had an influence on plant height and number of tillers. The responsiveness of sugarcane varieties to the treatment of Moringa leaf extract showed different result. BM 9044 varietiy responded to the treatment of dose of leaf extract of moringa at dose of $10 \mathrm{ml} / 1$, while the BM 9605 variety responded to the treatment of dose of moringa leaf extract at dose of $20 \mathrm{ml} / 1$, and BM 9514 variety responded to the dose of moringa leaf extract at $30 \mathrm{ml} / \mathrm{l}$.

Keywords: Dose, Moringa leaf extract, cytokinin, varieties of sugarcane, nursery
\end{abstract}

\begin{abstract}
ABSTRAK
Penelitian ini bertujuan untuk mengetahui dosis larutan daun kelor dalam meningkatkan pertumbuhan anakan beberapa varietas tanaman tebu serta untuk mengetahui perbedaan respon dari setiap varietas terhadap dosis yang diberikan. Rancangan penelitian yang digunakan adalah rancangan acak lengkap faktorial dua faktor dengan 5 kali ulangan. Faktor pertama yaitu perlakuan dosis ekstrak daun kelor $(0,10,20$, dan 30) dan $10 \mathrm{ml} / 1$ larutan sitokinin sintetik, dan faktor kedua adalah 3 varietas tanaman tebu (Varietas $1=$ BM 9514, varietas $2=$ BM 9044, dan varietas $3=$ BM 9605). Parameter pengamatan yaitu daya kecambah, tinggi tanaman, jumlah anakan, berat segar tanaman, berat kering tanaman, berat segar tajuk, berat kering tajuk, berat segar akar, berat kering akar, dan volume akar. Data dianalisis ragam dan di uji lanjut dengan Duncan Multiple Range Test (DMRT). Hasil penelitian menunjukan bahwa daya kecambah tertinggi pada varietas BM 9605 yaitu 97,4\%. Perlakuan ekstrak daun kelor memiliki pengaruh terhadap volume akar dan terdapat interaksi dosis dan varietas. Perlakuan varietas memiliki pengaruh terhadap tinggi tanaman dan jumlah anakan tanaman tebu. Responsibilitas tanaman tebu terhadap perlakuan ekstrak daun kelor memiliki hasil yang berbeda. Varietas BM 9044 sudah merespon perlakuan dosis ekstrak daun kelor dengan dosis $10 \mathrm{ml} / \mathrm{l}$ sedangkan Varietas BM 9605 merespon perlakuan dosis ekstrak daun kelor dengan dosis $20 \mathrm{ml} / \mathrm{l}$, dan Varietas BM 9514 merespon
\end{abstract}


perlakuan dosis ekstrak daun kelor dengan dosis $30 \mathrm{ml} / 1$.

Kata kunci : Dosis, ekstrak daun kelor, sitokinin, varietas tanaman tebu, pembibitan.

\section{PENDAHULUAN}

Tebu (Saccharum officinarum L.) merupakan tanaman monokotil yang tumbuh didaerah tropis dan sub-tropis diseluruh belahan dunia. Tanaman tebu mengandung sukrosa yang merupakan bahan baku industri gula. Gula sebagai produk olahan tebu, merupakan kebutuhan pokok rumah tangga dan sebagai bahan baku industri makanan dan minuman (Loganadhan et al., 2013). Peningkatan konsumsi gula tebu belum dapat diimbangi oleh produksi gula dalam negeri. Produksi tebu indonesia ditahun 2014, berdasarkan angka Tetap Statistik Perkebunan Indonesia (Ditjenbun, 2015), tercatat sebesar 2.579.173 ton. Produksi ini berasal dari 477.123 ha luas panen perkebunan tebu yang hanya berada di provinsi sumatera Utara, Gorontalo, Lampung, Sumatera Selatan.

Pembibitan tebu secara konvensional menggunakan bibit bagal dan rayungan, namun sekarang banyak digunakan bibit tebu yang berasal dari satu mata tunas yaitu bud set dan bud chip (Indrawanto et al., 2010). Pertumbuhan anakan tebu pada fase bibit merupakan faktor utama yang berpengaruh terhadap produksi tanaman tebu giling karena tumbuhnya anakan tebu yang serempak dapat meningkatkan jumlah produksi tanaman tebu (Natarajan, 2011).

Zat pengatur tumbuh (ZPT) merupakan senyawa organik bukan hara tetapi dapat merubah proses fisiologis tumbuhan. Gardner et al. (1991) menyatakan bahwa seringkali produksi zat pengatur tumbuh secara alami itu dibawah konsumsi optimal, maka dibutuhkan sumber dari luar untuk meningkatkan ZPT dalam tanaman dan menghasilkan respon posistif. Zat pengatur tumbuh memiliki potensi untuk meningkatkan keberhasilan pembibitan dengan cara mempercepat pertumbuhan, pembentukan akar dan tunas. Peran sitokinin dalam tumbuhan adalah mengatur pembelahan sel, pembentukan organ, pembesaran sel dan organ, pencegahan kerusakan klorofil, pembentukan kloroplas, pembukaan dan penutupan stomata, dan perkembangan mata tunas serta pucuk (Harjadi, 2009).
Tanaman kelor mengandung banyak senyawa yang dapat dimanfaatkan untuk obat maupun digunakan untuk merangsang pertumbuhan tanaman. Tanaman kelor mengandung hormon tumbuh yaitu sitokinin dan zeatin. Sitokinin merupakan hormon tanaman yang menginduksi pembelahan sel, pertumbuhan, dan mendorong pertumbuhan sel baru serta menunda penuaan sel. Zeatin merupakan anti oksidan kuat dengan sifat anti penuaan (Pusat Informasi dan Pengembangan Tanaman Kelor Indonesia, 2010). Ekstrak daun kelor meningkatan hasil panen sebesar $20-35 \%$, seperti diameter batang, jumlah akar, jumlah tunas, jumlah kuncup bunga, dan jumlah buah (Makkar dan Becker, 1996). Daun kelor dapat dimanfaatkan sebagai pupuk cair (Krisnadi, 2012).

Tanaman kelor diketahui mengandung sitokinin dan zeatin (Nager et al., 1982). Tanaman kelor diketahui memiliki konsentrasi zeatin yang berkisar antara 0,00002 $\mu \mathrm{g}$ sampai $0,02 \mu \mathrm{g} / \mathrm{g}$ (Krisnadi, 2015). Menurut Culver et al. (2012) menunjukan bahwa daun kelor dari berbagai belahan dunia memiliki konsentrasi zeatin tinggi antara 5-200 $\mu \mathrm{g} / \mathrm{g}$ daun.

Penelitian ini bertujuan untuk mengetahui dosis larutan daun kelor dalam meningkatkan pertumbuhan anakan beberapa varietas tanaman tebu serta untuk mengetahui perbedaan respon dari setiap varietas terhadap dosis yang diberikan.

\section{MATERI DAN METODE}

\section{Materi}

Penelitian dilaksanakan pada bulan November 2016 - Februari 2017, di pembibitan tanaman tebu Penelitian dan Pengembangan (Litbang) PTPN VII (Persero) Unit Usaha Bungamayang, Lampung Utara. Bahan yang digunakan dalam penelitian adalah daun tanaman kelor (Moringa oleifera), larutan sitokinin sintetik (Biotech Agro Indonesia), tanah, ampas tebu/blotong, larutan desinfektan, larutan fungisida, 3 varietas tanaman tebu yaitu BM 9514, BM 9044, BM 9605, polybag, pupuk urea, pupuk 
TSP, pupuk $\mathrm{KCl}$ dan air. Alat-alat yang digunakan yaitu blender, parang, gergaji potong, nampan, gelas ukur, timbangan analitik, cangkul, kantong plastik, oven, botol bekas air mineral, kain nilon, ayakan, gunting stek, selang, label, dan alat tulis.

\section{Metode}

Rancangan penelitian menggunakan rancangan acak lengkap (RAL) faktorial (5 x 3) dengan ulangan 5 kali. Faktor 1 adalah pemberian larutan daun kelor dan sitokinin sintetik yang terdiri dari 5 taraf perlakuan $(\mathrm{P})$ yaitu, $\mathrm{P} 1 /$ kontrol (tanpa perlakuan), P2 (larutan daun kelor 10 ml/liter), P3 (larutan daun kelor $20 \mathrm{ml} /$ liter), P4 (larutan daun kelor $30 \mathrm{ml} /$ liter), dan P5 (sitokinin sintetik $10 \mathrm{ml} /$ liter). Faktor 2 adalah 3 varietas tebu yang terdiri dari varietas $1=\mathrm{BM} 9514$, Varietas 2 $=$ BM 9044, dan Varietas $3=$ BM 9605. Penelitian memiliki 15 kombinasi perlakuan dengan 5 kali ulangan dengan jumlah keseluruhan adalah 75 tanaman.

Prosedur penelitian dimulai dari sterilisasi media tanam dan pemilihan bibit sesuai kebutuhan varietas dan berumur \pm 6 bulan setelah tanam. Bibit dipotong satu mata tunas dengan gergaji potong mekanis. Persemaian dilakukan pada potray (40 lubang/potray) dengan waktu persemaian selama 4 minggu. Ekstrak daun kelor diperoleh dengan cara diblender dengan ditambah aquadest. Larutan dan ampas dipisahkan dengan diperas menggunakan kain nilon. Timbang berat ampas dan ukur hasil larutan ekstrak daun kelor.

Sebelum digunakan ekstrak daun kelor dikocok terlebih dahulu untuk menghomogenkan larutan dengan endapan. Dosis ekstrak daun kelor $\mathrm{P} 1=0 \mathrm{ml} / 1$ aquadest, $\mathrm{P} 2=10 \mathrm{ml} / 1$ aquadest, $\mathrm{P} 3=$
$20 \mathrm{ml} / 1$ aquadest, $\mathrm{P} 4=30 \mathrm{ml} / 1$ aquadest, dan sitokinin sintetik pada $\mathrm{P} 5=10 \mathrm{ml} / 1$ aquadest. Bahan tanam disemai pada potrey dengan kapasitas satu lubang satu mata tunas dengan lama persemaian selama 4 minggu. Setelah fase persemaian tanaman dipindah ke fase pertumbuhan pada polybag besar yang berukuran $35 \times 40 \mathrm{~cm}$, dengan kapasitas 1 polybag 1 bibit bud set. Aplikasi ekstrak daun kelor bersamaan dengan penanaman bibit bud set dengan jumlah tanaman yaitu 75 tanaman dan diberi label. Tanaman dilakukan penyiraman minimal satu hari sekali dan pengamatan setiap satu minggu sekali. Pengamatan dilakukan selama 6 minggu setelah tanam dan kemudian dipanen untuk mengetahui kondisi berat segar dan berat kering tanaman.

Parameter yang diamati adalah daya kecambah, tinggi tanaman, jumlah anakan, dan volume akar. Analisis data menggunakan model linier rancangan acak lengakap faktorial dengan 5 ulangan. Data yang diperoleh dianalisis menggunakan analisis ragam (ANOVA) dan dilanjutkan dengan uji Duncan Multiple Range Test (DMRT) apabila terdapat pengaruh perlakuan terhadap variabel yang diamati.

\section{HASIL DAN PEMBAHASAN}

\section{Daya Kecambah Tanaman Tebu}

Fase persemaian belum diberikan perlakuan dosis ekstrak daun kelor maupun sitokinin sintetik. Daya kecambah relatif tinggi pada varietas 3 (BM 9605) sebesar 97,14\%, diikuti oleh varietas 1 (BM 9514) sebesar 85,71\% dan varietas 2 (BM 9044) sebesar 81,43\% (Tabel 1).

Varietas BM 9605 merupakan varietas

Tabel 1. Daya Kecambah 3 Varietas Tanaman Tebu

\begin{tabular}{cccc}
\hline Varietas & $\begin{array}{c}\text { Jumlah bibit bud set } \\
\text { semai }\end{array}$ & $\begin{array}{c}\text { Jumlah bibit semai } \\
\text { tumbuh }\end{array}$ & daya kecambah \\
\hline & --------mata-------- & ------- tunas------ & --------\%-------- \\
V1 (Bm 9514) & 70 & 60 & 85,71 \\
V2 (Bm 9044) & 70 & 57 & 81,43 \\
V3 (Bm 9605) & 70 & 68 & 97,14 \\
\hline Rata-Rata & 70 & 61,67 & 88,10 \\
\hline
\end{tabular}


unggulan yang dibudidayakan diareal tanam PTPN 7 sebagai tanaman yang dengan perkecambahan cepat dan seragam, memiliki tingkat adaptasi terhadap lingkungan yang tinggi, resisten terhadap serangan penggerek, memiliki produktifitas tinggi, dan rendemen tinggi. Varietas BM 9605 memiliki mata tunas dengan bentuk bulat telur dan menonjol dengan bagian terlebar berada ditengah mata yang dapat memudahkan mata tunas untuk tumbuh karena dibagian tengah mata memiliki kulit tertipis dibanding bagian yang lain (PTPN VII, 2009). Hasil penelitian Jain et al. (2010) menunjukan bahwa persemaian tanaman tebu dengan mata tunas tunggal bud set yang dikecambahkan menggunakan polybag dapat memberikan hasil yang baik (>95\%) daripada langsung ditanam pada areal tanam.

\section{Tinggi Tanaman Tebu}

Hasil analisis ragam menunjukkan bahwa perlakuan dosis ekstrak daun kelor maupun sitokinin sintetik tidak berpengaruh terhadap tinggi tanaman. Perlakuan varietas memiliki pengaruh dan terdapat interaksi antara dosis dan varietas terhadap tinggi tanaman dengan hasil yang tersaji pada Tabel 2 .
Berdasarkan perlakuan dosis ekstrak daun kelor pada tinggi tanaman tiga varietas tebu cendrung meningkat pada setiap tahap perlakuan dosis tetapi tidak berpengaruh terhadap tinggi tanaman. Terdapat interaksi dosis dan varietas yang berpengaruh terhadap tinggi tanaman dengan hasil perlakuan ekstrak daun kelor $30 \mathrm{ml} / 1$ pada varietas BM 9514 dengan tinggi $24,4 \mathrm{~cm}$, varietas BM 9044 pada perlakuan ekstrak daun kelor 10 $\mathrm{ml} /$ liter yaitu 23,6 cm, tetapi tidak berpengaruh terhadap varietas BM 9605 pada perlakuan ekstrak daun kelor $20 \mathrm{ml} /$ liter yaitu $25,6 \mathrm{~cm}$. Perlakuan ekstrak daun kelor pada tanaman tebu memberikan respon berbeda terhadap tinggi tanaman setiap varietas. Ekstrak daun kelor memiliki kandungan zeatin (sitokinin) (Nager, 1982). Sitokinin berfungsi dalam proses pembelahan sel tanaman, sedangkan penambahan panjang tanaman untuk memperoleh hasil optimal diperlukan kombinasi sitokinin dengan fitohormon lain. George et al. (2008) menyatakan bahwa penggunaaan sitokinin dengan konsentrasi rendah belum tentu dapat meningkatkan proses pemanjangan secara optimal dan dosis tinggi justru dapat menurunkan pertumbuhan tunas karena gagalnya sel dalam proses pemanjangan. Harjadi (2009) berpendapat bahwa pada fase

Tabel 2. Hasil Perlakuan Dosis Ekstrak Daun Kelor terhadap Tinggi Tanaman Tiga Varietas Tanaman Tebu

\begin{tabular}{|c|c|c|c|c|}
\hline \multirow[b]{2}{*}{ Perlakuan Dosis } & \multicolumn{2}{|c|}{ Varietas } & \multirow[b]{2}{*}{$\begin{array}{c}\text { V3 } \\
(\mathrm{BM} 9605)\end{array}$} & \multirow[b]{2}{*}{ Rata-rata } \\
\hline & $\begin{array}{c}\mathrm{V} 1 \\
\text { (BM 9514) }\end{array}$ & $\begin{array}{c}\mathrm{V} 2 \\
(\mathrm{BM} 9044)\end{array}$ & & \\
\hline & \multicolumn{4}{|c|}{--(cm)---1-- } \\
\hline P1 (kontrol) & $18,8 \mathrm{~cd}$ & $19,0 \mathrm{~cd}$ & $24,6 \quad a b$ & 20,80 \\
\hline $\begin{array}{l}\text { P2 (ekstrak daun kelor } 10 \\
\mathrm{ml} / \text { liter) }\end{array}$ & 21,0 abcd & $23,6 \quad a b$ & $18,2 \mathrm{~d}$ & 20,93 \\
\hline $\begin{array}{l}\text { P3 (ekstrak daun kelor } 20 \\
\text { ml/liter) }\end{array}$ & 21,0 abcd & $19,0 \mathrm{~cd}$ & $25,6 \quad a$ & 21,87 \\
\hline $\begin{array}{l}\text { P4 (ekstrak daun kelor } 30 \\
\text { ml/liter) }\end{array}$ & $24,4 \quad a b$ & $19,8 \quad b c d$ & $22,2 \quad a b c$ & 22,13 \\
\hline $\begin{array}{l}\text { P5 (ekstrak sitokinin } 10 \\
\mathrm{ml} / \text { liter) }\end{array}$ & $24,4 \quad a b$ & $19,2 \mathrm{~cd}$ & $23,4 \quad a b$ & 22,23 \\
\hline Rata-rata & $21,9 \quad \mathrm{a}$ & $20,1 \quad b$ & $22,8 \quad \mathrm{a}$ & \\
\hline \multicolumn{5}{|l|}{ Keterangan } \\
\hline
\end{tabular}


pemanjangan batang terjadi perlambatan pada fase pertumbuhan tunas. Pemanjangan batang berlangsung pada stadia pertumbuhan yaitu umur 3-9 bulan.

\section{Jumlah Anakan Tanaman Tebu}

Hasil analisis ragam menunjukkan bahwa perlakuan dosis tidak berpengaruh terhadap jumalah anakan dan tidak terdapat interaksi dosis dan varietas. Perlakuan varietas memberikan pengaruh terhadap jumlah anakan tanaman tebu. Perlakuan dosis ekstrak daun kelor terhadap jumlah anakan tiga varietas tanaman tebu tersaji pada Tabel 3.

Perlakuan dosis ekstrak daun kelor tidak berpengaruh terhadap jumlah anakan 3 varietas tebu dan perlakuan varietas paling responsif terhadap perlakuan dosis ekstrak daun kelor adalah varietas BM 9514 sebesar 8,9 anakan diikuti oleh varietas BM 9044 dan BM 9605, masing-masing 8,0 dan 6,2 anakan. Interaksi dosis dan varietas tidak berpengaruh terhadap peningkatan jumlah anakan. Menurut Sato dan Mori (2001) yang menunjukan bahwa pembentukan anakan pada tanaman memerlukan peran dari auksin yang berfungsi menghambat pertumbuhan tunas apikal dan sitokinin untuk mendorong pertumbuhan tunas lateral. Khuluq dan Hamida (2014) menyatakan bahwa fase pertunasan merupakan proses keluarnya anakan baru dari pangkal tebu muda (tunas primer) yang berlangsung selama \pm 5 minggu. Harjanti (2014) berpendapat bahwa tanaman tebu memiliki kemampuan untuk membentuk anakan dalam satu rumpun, yang merupakan hal terpenting dalam pertumbuhan tanaman tebu. Semakin tinggi jumlah anakan semakin tinggi pula produksi yang yang dihasilkan.

\section{Volume Akar Tanaman Tebu}

Hasil analisis ragam menunjukkan bahwa perlakuan dosis ekstrak daun kelor terdapat pengaruh terhadap volume akar, terdapat interaksi dosis dan varietas, tetapi perlakuan varietas tidak berpengaruh terhadap volume akar tanaman tebu yang tersaji pada Tabel 4.

Perlakuan ekstrak daun kelor terhadap volume akar 3 varietas tanaman tebu memberikan peningkatan hasil dengan nilai tertinggi pada perlakuan ekstrak sitokinin $10 \mathrm{ml} /$ liter (P5) dan tidak berbeda nyata dengan perlakuan ekstrak daun kelor $20 \mathrm{ml} /$ liter (P3) dengan notasi yang

Tabel 3. Hasil Perlakuan Dosis Ekstrak Daun Kelor terhadap Jumlah Anakan Tiga Varietas Tanaman Tebu

\begin{tabular}{|c|c|c|c|c|}
\hline \multirow[b]{2}{*}{ Perlakuan Dosis } & \multicolumn{2}{|c|}{ Varietas } & \multirow[b]{2}{*}{$\begin{array}{c}\text { V3 } \\
(\mathrm{BM} 9605)\end{array}$} & \multirow[b]{2}{*}{ Rata-rata } \\
\hline & $\begin{array}{c}\mathrm{V} 1 \\
\text { (BM 9514) }\end{array}$ & $\begin{array}{c}\mathrm{V} 2 \\
\text { (BM 9044) }\end{array}$ & & \\
\hline & & $----(\mathrm{a}$ & an)---. & -- \\
\hline P1 (kontrol) & $8,6 \quad a b c$ & 7,8 abcde & 7,0 bcdef & 7,8 \\
\hline $\begin{array}{l}\text { P2 (ekstrak daun kelor } 10 \\
\mathrm{~m} 1 / \text { liter) }\end{array}$ & $8,8 \quad a b c$ & 8,4 abcd & 6,2 ef & 7,8 \\
\hline $\begin{array}{l}\text { P3 (ekstrak daun kelor } 20 \\
\text { m1/liter) }\end{array}$ & $9,2 \quad a b$ & $9,2 \quad a b c$ & 6,2 def & 8,2 \\
\hline $\begin{array}{l}\text { P4 (ekstrak daun kelor } 30 \\
\mathrm{ml} / \text { liter) }\end{array}$ & 8,2 abcd & 6,8 bcde & 6,0 ef & 7,0 \\
\hline $\begin{array}{l}\text { P5 (larutan sitokinin } 10 \\
\text { ml/liter) }\end{array}$ & $9,8 \quad \mathrm{a}$ & 7,8 cde & $5,4 \mathrm{f}$ & 7,7 \\
\hline Rata-rata & $8,9 \quad \mathrm{a}$ & $8,0 \quad \mathrm{~b}$ & $6,2 \quad \mathrm{c}$ & 7,7 \\
\hline $\begin{array}{l}\text { Angka ya } \\
\text { duncan p } \\
\text { Angka ya } \\
\text { duncan p }\end{array}$ & $\begin{array}{l}\text { ti huruf yang } \\
\text { nyata } 5 \% \text {. } \\
\text { i huruf yang } \\
\text { nyata } 5 \% \text {. }\end{array}$ & $\begin{array}{l}\text { pada baris rat } \\
\text { ada matrik in }\end{array}$ & $\begin{array}{l}\text { tidak berbeda } \\
\text { i tidak berbeda }\end{array}$ & a menurut $u_{-}$ \\
\hline
\end{tabular}


Tabel 4. Hasil Perlakuan Dosis Ekstrak Daun Kelor terhadap Volume Akar Tiga Varietas Tanaman Tebu

\begin{tabular}{|c|c|c|c|c|c|}
\hline \multirow[b]{2}{*}{ Perlakuan dosis } & \multicolumn{2}{|c|}{ Varietas } & & \multirow{2}{*}{\multicolumn{2}{|c|}{ Rata-rata }} \\
\hline & $\begin{array}{c}\mathrm{V} 1 \\
\text { (BM 9514) }\end{array}$ & $\begin{array}{c}\mathrm{V} 2 \\
(\mathrm{BM} 9044)\end{array}$ & $\begin{array}{c}\mathrm{V} 3 \\
(\mathrm{BM} 9605)\end{array}$ & & \\
\hline \multirow[b]{2}{*}{ P1 (kontrol) } & & & )- & --- & \\
\hline & $147,4 \quad a b c$ & 109 bcd & $99,0 \quad \mathrm{~d}$ & 118,5 & $\mathrm{c}$ \\
\hline $\begin{array}{l}\text { P2 (ekstrak daun kelor } 10 \\
\mathrm{~m} 1 / \text { liter) }\end{array}$ & 125,0 abcd & $150 \mathrm{abc}$ & $111,0 \quad \mathrm{~cd}$ & 128,7 & bc \\
\hline $\begin{array}{l}\text { P3 (ekstrak daun kelor } 20 \\
\mathrm{ml} / \text { liter) }\end{array}$ & 132,6 abc & 125 abcd & $163,0 \quad a$ & 140,2 & $\mathrm{ab}$ \\
\hline $\begin{array}{l}\text { P4 (ekstrak daun kelor } 30 \\
\mathrm{ml} / \text { liter) }\end{array}$ & 138,4 abc & 140 abc & 120,6 abcd & 133,0 & $a b c$ \\
\hline $\begin{array}{l}\text { P5 (larutan sitokinin } 10 \\
\text { m1/liter) }\end{array}$ & $165,2 \quad a$ & 146 abc & $155,4 \quad a b$ & 155,5 & $\mathrm{a}$ \\
\hline Rata-rata & 141,7 & 134 & 129,8 & 135,2 & \\
\hline $\begin{array}{l}\text { Keteranga } \\
\mathrm{n}:\end{array}$ & $\begin{array}{l}\text { uruf yang sa } \\
\text { a } 5 \% \text {. } \\
\text { uruf yang sa } \\
\text { a } 5 \% \text {. }\end{array}$ & kolom ra & $\begin{array}{l}\text { tidak berbeda } \\
\text { tidak berbed }\end{array}$ & & \\
\hline
\end{tabular}

sama yaitu 155,5a dan 140,2ab. Tidak terdapat interaksi dosis dan varietas dengan adanya peningkatan pada varietas BM 9044 dan BM 9605 tetapi berbeda dengan varietas BM 9514. Perlakuan ekstrak daun kelor maupun sitokinin sintetik mampu meningkatkan volume akar pada masing-masing varietas. Dosis pada varietas BM 9514 perlu di tingkatkan untuk mengetahui batas optimal yang dapat meningkatkan volume akar.

Berat segar akar dan panjang akar tanaman berpengaruh pada volume akar tanaman. Menurut Krishnamoorthty et al. (1981) peningkatan jumlah akar dapat disebabkan oleh semakin tingginya aktifitas metabolisme sel yang membelah. Sel yang terbentuk akan membesar dan berdeferensiasi sehingga meningkatkan volume akar. Fodhil (2012) menunjukkan bahwa jumlah akar yang terbentuk akan menentukan volume akar. Apabila jumlah akar yang terbentuk banyak, maka kemampuan akar menyerap unsur hara semakin tinggi dan hasil dari fotosintesis dapat dialokasikan keseluruh bagian tanaman termasuk untuk pertumbuhan akar.

\section{KESIMPULAN}

Berdasarkan pembahasan diketahui bahwa perlakuan ekstrak daun kelor memiliki pengaruh terhadap volume akar dan terdapat interaksi dosis dan varietas. Perlakuan varietas memiliki pengaruh terhadap tinggi tanaman dan jumlah anakan tanaman tebu. Responsibilitas tanaman tebu terhadap perlakuan ekstrak daun kelor memiliki hasil yang berbeda. Varietas BM 9044 sudah merespon perlakuan dosis ekstrak daun kelor dengan dosis $10 \mathrm{ml} / 1$ sedangkan Varietas BM 9605 merespon perlakuan dosis ekstrak daun kelor dengan dosis $20 \mathrm{ml} / 1$, dan Varietas BM 9514 merespon perlakuan dosis ekstrak daun kelor dengan dosis $30 \mathrm{ml} / 1$.

\section{DAFTAR PUSTAKA}

Culver, M., T. Fanuel, dan A. Z. Chiteka. 2012. Effect of Moringa Extract on Growth and Yield of Tomato. Green Journal of Agricultural Sciences. Vol. 2 (5) : 207-211. 
Dinas Perkebunan Provinsi Jawa Timur. 2013. Pengawasan Benih Tanaman (PBT). Pusat Penelitian Gula PTPN X (Persero). Jengkol, Kediri.

Fodhil, M., Armaini, dan Nurbaiti. 2012. Pengaruh Konsentrasi Air Kelapa pada Pembibitan Tanaman Buah Naga (Hylocereus costaricencis). Bengkalis.

Gardner, F.P., Pearce, R.B., dan Mitchell R.L. 1991. Fisiologi Tanaman Budidaya. Penerjemah Susilo, $\mathrm{H}$ dan Pendamping Subiyanto. Cetakan Pertama. Penerbit Universitas Indonesia Press, Jakarta.

Harjadi. 2009. Zat Pengatur Tumbuh . Penebar Swadaya. Jakarta.

Harjanti, R. A., Tohari, dan S. N. H. Utami. 2014. Pengaruh Takaran Pupuk Nitrogen dan Silika terhadap Pertumbuhan Awal (Saccharum officinarum L.) pada Inceptisol. Fakultas Pertanian Universitas Gajah Mada Yogyakarta. Vegetalika. Vol. 3 (2) : 35-44.

Indrawanto, C., Purwono, Siswanto, M. Syakir, dan W. Rumini. 2010. Budidaya dan Pasca Panen Tebu. Eska Media, Jakarta.

Khuluq, A. D., dan R. Hamida. 2014. Peningkatan Produktifitas dan Rendemen Tebu melalui Rekayasa Fisiologis Pertunasan. Balai Penelitian Tanaman Pemanis dan Serat. Malang. J. Perspektif. Vol. 13 (1) : 13-24.
Krisnadi, A.D. 2015. Kelor Super Nutrisi. Edisi Revisi. Pusat Informasi dan Pengembangan Tanaman Kelor Indonesia, Lembaga Swadaya Masyarakat - Media Peduli Lingkungan (LSM-MEPELING). Kunduran, Blora.

Loganandhan, N., B. Gujja, V.V. Goud, dan U.S. Natarajan. 2013. Sustainable Sugarcane Initative (SSI): A methodology of more mith less. India. Journal Sugar Tech vol.15, Issue $1: 98-102$.

Nager, P.K., Iyer, R.L., and Sircar, P.K. 1982. Cytokinins in developing fruits of Moringa pteriogosperma Gaertn. Physiol. Plant. 55 : 45-50.

Natarajan, U.S. 2011. Tillering in SSI Emergence, Factors Affecting, Contraints and Solutions. First Nasional Seminar on Sugarcane Sustainable Initiative : 21-23.

PTPN VII (persero). 2009. Laporan tahunan PTPN VII (persero) Pabrik Gula Bungamayang. Lampung Utara.

Pusat informasi dan pengembangan tanaman kelor Indonesia. 2010. Kelor Super Nutrisi. Lembaga Swadaya Masyarakat - Media Peduli Lingkungan (LSM-MEPELING). Blora.

Sato, S. S., dan H. Mori. 2001. Control of Outgrowth and Dormancy in Axillary Buds. Plant Physiology, Vol. 127, pp. 14051413. 